\title{
Lets Address Health and Well-Being in Our Profession
}

\author{
Charles N. Cornell, MD
}

Received: 26 July 2015/Accepted: 31 July 2015/Published online: 8 September 2015

(C) Hospital for Special Surgery 2015

Welcome to Volume 11 issue 3 of HSS Journal. I am happy to report that the journal is doing well with an increasing readership from around the world. If we accept online downloads of complete articles, an indicator, our readership is growing steadily. In 2014, over 54,000 downloads were requested by readers throughout the globe. We are continuing to strive to make our content relevant and of interest to our readers.

This issue has a wide variety of articles from musculoskeletal medicine and surgery. Included is a commentary written by three of our residents. In " 24 Hour Fitness: The Orthopedic Resident On Call Work-out," they explore the importance of participation in exercise and wellness as orthopedic residents. They review a fairly extensive literature concerned with the health and well-being of physicians in training and the effect on not only their own health but also the safety of their patients. They propose a simple but seemingly thorough workout using the materials at hand in a typical call room [1].

Remarkably, very little is documented about the health and well-being of physicians and especially surgeons. A career in medicine can be extremely rewarding but the stresses of lifelong practice can be devastating. We are all aware of colleagues who have succumbed to the rigors of practice, but it surprises me that so little has been done to systematically identify the health risks of medical practice. Shanafelt and colleagues of the Mayo Clinic have written extensively on the well-being of residents and physicians and have focused particularly on surgeons [2]. They have surveyed the American College of Surgeons and found that $55 \%$ state that they practice aerobic exercise and only $35 \%$

Electronic supplementary material The online version of this article (doi:10.1007/s11420-015-9461-9) contains supplementary material, which is available to authorized users.

C. N. Cornell, MD $(\bowtie)$

Hospital for Special Surgery,

535 East 70th Street,

New York, NY 10021, USA

e-mail: cornellc@hss.edu include muscle strengthening. That being the case, only a minority of American surgeons follow CDC guidelines for health maintenance through exercise. They further document how adoption of wellness strategies helps reduce the risk of burnout during a surgical career.

I congratulate Derman and his co-authors on drawing attention to this important but neglected issue. We need more research on the impact of a surgical career on the health of surgical practitioners and how exercise and wellness strategies can prevent burnout and other degenerative disease risks inherent to our profession. I find it troubling that so much effort has been put into documenting exposure to radiation in orthopedic surgeons while little is known of the risk of degenerative arthritis, coronary artery disease, and mental illness in what appears to be a very high-risk population.

\section{Disclosures}

Conflict of Interest: Charles N. Cornell, MD has declared that he has no conflict of interest.

Human/Animal Rights: This article does not contain any studies with human or animal subjects performed by the any of the authors.

Informed Consent: N/A

Required Author Forms Disclosure forms provided by the authors are available with the online version of this article.

\section{References}

1. Derman PB, Liu J, McLawhorn AS. 24-hour fitness: the orthopedic resident on-call workout. HSS Journal. doi:10.1007/s11420-0159441-0

2. Shanafelt TD, Kaups KL, Nelson H, et al. An Interactive Individualized Intervention to Promote Behavioral Change to Increase Personal Well-Being in US Surgeons. Ann Surg. 2014; 259(1):828. doi:10.1097/SLA.0b013e3182a58fa4. 